\title{
Cytotoxic Drugs Safety Guidelines: Its Effect on Awareness and Safe Handling Practices of Oncology Nurses
}

\author{
Naglaa Elsayed Mahdy ${ }^{1}$, Asmaa Abdel Rahman Abdel Rahman ${ }^{1}$, \\ Heba Ali Hassan ${ }^{2}$ \\ ${ }^{1}$ Medical Surgical Nursing department, Faculty of Nursing, Ain Shams University, Cairo, Egypt \\ ${ }^{2}$ Nursing Administration Department, Faculty of Nursing, Ain Shams University, Cairo, Egypt
}

\begin{abstract}
Cytotoxic agents have been associated with major concerns among oncology nurses and could result in nurses' exposure to these drugs and consequent side effects. This study aimed to evaluate the effect of cytotoxic drugs safety guidelines on knowledge, safe handling practices and attitude of oncology nurses through the following:(1) Assessment of knowledge, handling practices and attitude of oncology nurses toward cytotoxic drugs. (2) Developing and implementing cytotoxic drugs safety guidelines. (3) Evaluating the effect of cytotoxic drugs safe-handling guidelines on knowledge, handling practices and attitude of oncology nurses. (4) Assessment of factors affecting oncology nurses' safe handling practices of cytotoxic drugs. A quasiexperimental design was utilized to conduct this study. The study was conducted at the cancer center affiliated to Ain Shams University Hospitals, Egypt. A purposive sample of 65 nurses who are working in the cancer center and handling cytotoxic drugs was included in the study. Data collection tools: (1) A self-administered nurses' knowledge assessment questionnaire regarding cytotoxic anticancer drugs and its safe handling precautions. (2) Nurses' cytotoxic drugs safe handling practices observational checklist. (3) Five-points likert nurses' attitude scale. (4) Factors affecting oncology nurses' safe handling practices of cytotoxic drugs questionnaire. There were highly statistically significant differences between mean scores of the pre and post guidelines intervention of nurses' knowledge, practices and attitude regarding safe handling of cytotoxic drugs. Conclusion: Implementation of the cytotoxic drugs safe-handling guidelines has positive effect on improving the knowledge, practice and attitude of oncology nurses working in the cancer center affiliated to Ain Shams University Hospital. Recommendations: Conducting periodic in-services training program for oncology nurses handling cytotoxic drugs in the cancer center to improve safety handling measures and reduce risk exposure.
\end{abstract}

Keywords: Cytotoxic drugs, Safety guidelines, Safe handling, Oncology nurses.

\section{Introduction}

Cytotoxic is often used to refer to any agent that may be hazardous to the cells in any way. Cytotoxic drugs (CDs) or antineoplastic drugs are therapeutic agents that used for the treatment of cancer [1]. These drugs are mainly used in chemotherapy for their actions on killing cancerous cells, and are known to be mutagenic, teratogenic, and carcinogenic to humans [2]. However, their non-selective mechanism of action affects both cancerous and non-cancerous cells, resulting in well documented side effects [3].

Direct exposure of health care providers to cytotoxic drugs can occur during admixture, transport, preparation, and administration, as well as during waste handling and equipment maintenance and repair. Nurses are among the main groups of professionals that are involved in these activities and have the potential for exposure to these drugs in patient care settings [2].

The typical routes of exposure involve drug inhalation, ingestion, or absorption and accidental needle stick injury during the process of handling. Oncology nurses may inhale droplets, particulates, and vapors when these drugs create aerosols during drug preparation or while cleaning up spills. Dermal exposure may occur when the nurses touch contaminated surfaces during the preparation, administration, or disposal of hazardous chemotherapy drugs or patient wastes, and oral exposure may occur from hand-to-mouth contact or ingestion of contaminated food or drink. Other drug manipulations and work tasks also involve activities that may result in exposure through inhalation, skin contact, ingestion, or injection $[4,5]$.

The health risks associated with exposure to cytotoxic drugs are well documented. Health effects associated with cytotoxic drugs exposure has been reported to result in skin rashes or discolorations, sore throat, cough, dizziness, headache, blurred vision, eye irritation, hair loss, and allergic reactions [6]. Oncology nurses who exposed to cytotoxic drugs have increased risk of leukemia and other cancers. Unprotected persons who handle these drugs have shown DNA damage, infertility, miscarriage, premature birth, and congenital problems $[7,8]$. 
Organizations such as National Institute for Occupational safety and Health administration (NIOSH), American Society of Hospital Pharmacist (ASHP), the Oncology Nursing Society, and Occupational Safety and Health Administration (OSHA) have recommended safe handling guidelines for cytotoxic drugs [9]. All these guidelines recommend a combination of hazard controls that include; (1) engineering solutions to physically isolate the worker from drug exposure, to the extent possible; (2) administrative controls and work practices that further minimize drug contact through a designated organization of work, specialized worker training, and specified methods used to perform work tasks; and (3) use of personal protective equipment and apparel to minimize drug contact with the skin or respiratory tract [5].

Nurses must be aware of the existing hazards and safe handling practices of cytotoxic drugs because it has been associated with improvement of safety of both; patients and nurses. The recommended methods for reducing hazard drugs (HDs) exposure include 1) biological safety cabinets (BSCs) to protect against inhalation exposure during drug preparation; 2) two pairs of disposable gloves that are powder free and have been tested for use with HDs; 3 ) a disposable gown made of chemical-protective fabric with long sleeves, cuffs and back closure; 4) a respirator to protect against aerosols; 5) eye and face shield that provides splash protection; 6) administrative controls and 7) careful work practices to reduce opportunities for exposure. All precautions, when used consistently, can reduce occupational exposure to HDs [10]. The higher the nurses' awareness, the more they adhere to the use of safety measures in their practices, and this in turn contributes to their sense of well-being [6].

\subsection{Significance of the study:}

Cytotoxic drugs are being handled, prepared and administered in the cancer center affiliated to Ain Shams university hospital by oncology nurses, this may make them vulnerable to exposure to low doses of the drugs by direct contact, inhalation, and ingestion. It is known that cytotoxic drugs are associated with secondary formation of cancers and chromosome abnormalities. Additionally, nausea, vomiting, dizziness, alopecia, and nasal mucosal ulcerations have been reported in nurses who have handled cytotoxic drugs. Because of known and potential hazards associated with handling cytotoxic drugs, it is important for oncology nurses to be aware of the safety precautions for handling these drugs in order to avoid or reduce the potential harmful effects results from exposure to cytotoxic drugs and improve the safety of nurses. So that, this study aims to evaluate the effect of cytotoxic drugs safety guidelines on knowledge, handling practices and attitude of oncology nurses who involved in the preparation and administration of cytotoxic drugs.

\subsection{Aim of the study:}

This study aims to evaluate the effect of cytotoxic drugs safety guidelines on awareness, safe handling practices and attitude of oncology nurses through the following: (1) Assessment of knowledge, handling practices and attitude of oncology nurses toward cytotoxic drugs. (2) Developing and implementing cytotoxic drugs safety guidelines. (3) Evaluating the effect of cytotoxic drugs safe-handling guidelines on knowledge, handling practices and attitude of oncology nurses. (4) Assessment of factors affecting oncology nurses' safe handling practices of cytotoxic drugs.

\subsection{Research hypothesis:}

This study hypothesized that:

1. Implementation of cytotoxic drugs safety guidelines will affect positively on the knowledge of oncology nurses.

2. Implementation of cytotoxic drugs safety guidelines will affect positively on the handling practices of oncology nurses.

3. Implementation of cytotoxic drugs safety guidelines will affect positively on the attitude of oncology nurses.

\subsection{Research design:}

\section{Methods}

A quasi-experimental research design with one group pre-test, post-test was used to conduct this study.

2.2 Setting:

The study was conducted in the cancer center affiliated to Ain Shams University Hospitals, Cairo, Egypt.

2.3 Subjects:

A purposive sample of 65 nurses who are working in the cancer center and handling cytotoxic drugs, from both genders with different educational levels, and agreed to participate in the study.

\subsection{Tools for data collection:}

Four tools for data collection were used as follow: 


\subsubsection{A self-administered nurses' knowledge assessment questionnaire regarding cytotoxic anticancer drugs and its safe handling precautions:}

This questionnaire was developed by the researchers in an Arabic language based on the review of related literatures (Polovich and Clark, 2010; Polovich, Olsen, LeFebvre, 2014) [11, 12] to assess nurses' knowledge regarding cytotoxic anticancer drugs safe handling. It included four parts as follow:

- Part 1 was used to assess nurses' demographic characteristics such as age, gender, marital status, qualification, and years of experiences in administering cytotoxic anticancer drugs.

- Part 2 was used to assess previous training courses including (cytotoxic anticancer drugs administration, safe handling measures of cytotoxic drugs, and health hazards resulting from exposure to cytotoxic drugs), nurses' role (either preparation or administration of cytotoxic drugs), frequency of administration, number of patients received cytotoxic drugs by every nurse daily.

- Part 3 was used to assess complain or effect of exposure to cytotoxic anticancer drugs on nurses, and periodic health follow-up for nurses.

- Part 4 included 55 true and false questions grouped into three subgroups to assess nurses' knowledge regarding the following: cytotoxic anticancer drugs and its hazardous effects (12 questions), methods of exposure to cytotoxic drugs (13 questions) and safe handling measures (30 questions).

\section{Scoring system}

The fourth part which was concerned with assessment of nurses' knowledge consisted of 55 questions; the responses for the questions were either by true or false. The correct answer was given (1 grade), the incorrect answer was given (zero), the total grade for the knowledge questionnaire was (55 grades), the total scores for every subgroup were calculated, and then the total score for the entire questionnaire was calculated for every nurse. Then the mean of the total score for all nurses was calculated.

\subsubsection{Nurses' cytotoxic drugs safe handling practices observational checklist:}

This checklist was used to assess nurses' practices regarding safe handling practices of cytotoxic anticancer drugs. It was developed by the researchers based on the review of related updated literatures (Yarbro, Wujcik and Gobel, 2011; Connor, Eckel, McDiarmid, Polovich and Power, 2013; OSHA, 2016) [2, 5, 10]. It included 63 practice steps which were distributed into 6 parts as following:

- Part 1 was used to assess nurses' practices regarding safe handling practices during preparation of cytotoxic anticancer drugs. It includes (19 steps).

- Part 2 was used to assess nurses' practices regarding safe handling practices during transportation of cytotoxic anticancer drugs. It includes (6 steps).

- Part 3 was used to assess nurses' practices regarding safe handling practices during administration of cytotoxic anticancer drugs. It includes (15 steps).

- Part 4 was used to assess nurses' practices regarding safe handling practices during discontinuation of cytotoxic anticancer drugs. It includes (8 steps).

- Part 5 was used to assess nurses' practices regarding safe handling practices during waste disposal and spillage management of cytotoxic anticancer drugs. It includes (8 steps).

- Part 6 was used to assess nurses' practices regarding safe handling practices during care of safety cabinet (5 items) and documentation of exposure (2 steps).

\section{Scoring system}

The responses for the 63 practice steps were either by done correctly or done incorrectly. One grade was given for each correct step and zero for each incorrect or not done step. The total scores for the observation checklist were (63 grades). The total scores for every subgroup were calculated, and then the total score of the entire checklist was calculated for every nurse. Then the mean of the total score for all nurses was calculated.

\subsubsection{Five-point likert nurses'attitude scale:}

This tool was was adopted from (Polovich and Clark, 2010) [11] and translated into an Arabic language and back translated by the researchers in order to assess nurses' attitude toward safe handling practices of cytotoxic anticancer drugs. It included 11 statements. The nurses were asked to rate their responses on a fivelikert scale ranged from strongly agree to strongly disagree. The attitude scale included 6 positive and 5 negative statements. A five-point likert scale has the advantages of allowing neutrality and has enough gradation to give meaningful data, yet not be too tedious. It eases of expressing true opinion; considered more positive, more precise, and introduce more choice.

\section{Scoring system}

This tool is consisted of 11 statements. The responses for the positive attitude statements were on a five-likert scale where $5=$ strongly agree, $4=$ agree, $3=$ neutral (undecided), $2=$ disagree, $1=$ strongly disagree. The 
responses for the negative attitude statements were on a five-likert scale where $1=$ =strongly agree, $2=$ agree, $3=$ neutral (undecided), $4=$ disagree, $5=$ strongly disagree. The total score of the attitude scale was ( 55 score). The total score for the whole attitude scale was calculated for every nurse. Then the mean of the total score for all nurses was calculated. The highest score indicate positive attitude.

\subsubsection{Factors affecting oncology nurses' safe handling practices of cytotoxic drugs questionnaire:}

This tool was developed by the researchers in an Arabic language based on the review of related literatures (Polovich, Clark, 2012; Chaudhary, Karn, 2012) [13,14] to assess the factors that affect oncology nurses' use of cytotoxic anticancer drugs safe handling practices. It included 18 statements which were grouped into 5 subgroups as follow: safe handling awareness of cytotoxic drugs ( 3 items), adequacy of equipments (5 items), working environment ( 2 items), workload (5 items), and administrative ( 3 items).

\section{Scoring system}

The responses for the 18 statements were either by yes or no. One grade was given for (yes) response while zero for (no) response.

\subsection{Tool validity and reliability:}

- These questionnaires were reviewed by a panel of 5 experts ( 1 medical oncologist in faculty of medicine, 2 professors and 2 assistants professors in medical surgical nursing department, Ain Shams University) in order to evaluate its face and content validity. The experts reviewed the tools for its content, clarity, simplicity, relevance, comprehensiveness, appropriateness and applicability. Minor modifications were done and then the final forms of the tools were developed.

- Testing the reliability of the purposed data collecting tools was done by alpha cronbach test which was 0.82 for the knowledge and 0.93 for the practice tool and was 0.86 for the attitude.

\subsection{Pilot study:}

A pilot study was carried out on $10 \%$ of nurses to test the applicability of the study and to test clarity of the designed questionnaires, as well as to estimate the time needed for each tool. The modifications were done for the used tools then the final form was developed. Nurses of the pilot study were included in the study's subjects.

\subsection{Ethical considerations:}

The research approval was obtained from the faculty of nursing research ethics committee before initiating the study. The researcher clarified the purpose and aim of the study to nurses included in the study. Oral consent was obtained from nurses to ensure willingness to engage in the study. The researcher maintained anonymity and confidentiality of subjects' data. Nurses were informed that they are allowed to withdraw from the study at any time without penalty.

\subsection{Procedure:}

The procedure included three phases: preparatory phase, implementation phase and evaluation phase.

\subsubsection{Preparatory phase:}

This phase involved extensive reviewing of the recent related literatures to develop tools for data collection. The aim and purpose of the study was explained by the researchers to the study subjects prior to data collection, as well as their approval to participate in the study was obtained. The previous questionnaires were distributed to the nurses to complete it by themselves in the presence of the researchers in order to assess nurses' knowledge and attitude regarding safe handling of cytotoxic drugs to identify the nurses' learning needs. It took 30-45 minutes to fill these questionnaires. Then the observation checklists were used to observe every nurse one time by the researcher before implementation of the guidelines. It took 30 minutes to fill in these checklists. The researchers developed the guidelines booklet about cytotoxic anticancer drugs safe handlings practices in an Arabic language including terminologies, indications of use of cytotoxic anticancer drugs, types, hazardous effects of cytotoxic anticancer drugs on nurses, methods of exposure, safe handling measures regarding (personal protective equipments, transportation, preparation, administration and discontinuation of cytotoxic drugs, waste disposal and spillage management, care of safety cabinet and documentation of exposure). The educational guidelines were revised for content validity by a group of five expertise ( 3 professors in medical surgical nursing department and 2 assistant professors in medicine faculty) and the final modifications was done based on the opinion of the expertise.

\subsubsection{Implementation phase:}

The teaching sessions were conducted for nurses at the cancer center. The guidelines booklet was distributed for nurses under study. The contents of the guidelines booklet were explained over 4 sessions with 
45 minute for every session. All nurses were divided into 5 groups and each group received the four sessions separately to minimize interruption of nurses' work. The first teaching session included: the theoretical part (terminologies, indications of use of cytotoxic anticancer drugs, types, hazardous effects of cytotoxic anticancer drugs on nurses, methods of exposure. While the second, third and the fourth sessions included practical part about safe handling measures regarding (personal protective equipments, transportation of cytotoxic drugs, preparation, administration and discontinuation of cytotoxic drugs, waste disposal and spillage management, care of safety cabinet and documentation of exposure). Lecture and small group discussion were used for giving the theoretical part, while demonstration and re-demonstration was used for practical part. Data collection and teaching sessions were conducted over a period of six months starting at September 2016 till the end of February 2017 in the morning shifts.

\subsubsection{Evaluation phase:}

Post implementation of the guidelines sessions, all tools were filled in again immediately. Evaluation of the effect of the guidelines was done by comparing the results of nurses' knowledge, practice and attitude pre and post the implementation of guidelines sessions by using the same data collection tools.

\subsection{Data analysis:}

The collected data were analyzed using the statistical package for social science (SPSS) version 18. Quantitative data were presented as mean and standard deviation (SD), t-test was used to determine the differences. Qualitative data were presented as percentage (\%). The significance of the observed difference was obtained at $\mathrm{P}=0.05$.

\section{Results}

Table (1): Demographic characteristics of the studied nurses $(\mathrm{N}=65)$

\begin{tabular}{|c|c|c|}
\hline Nurses' characterisitcs & No & $\%$ \\
\hline \multicolumn{3}{|l|}{ Age group (years) } \\
\hline $20-<30$ & 23 & 35.3 \\
\hline $30-<40$ & 25 & 38.5 \\
\hline 40 and more & 17 & 26.2 \\
\hline \multicolumn{3}{|c|}{$33.51 \pm 8.59$} \\
\hline \multicolumn{3}{|l|}{ Gender } \\
\hline Female & 56 & 86.2 \\
\hline Male & 9 & 13.8 \\
\hline \multicolumn{3}{|l|}{ Level of education: } \\
\hline Bachelor degree & 13 & 20.0 \\
\hline Diploma & 47 & 72.3 \\
\hline Technical Institute & 5 & 7.7 \\
\hline \multicolumn{3}{|l|}{ Marital status: } \\
\hline Single & 15 & 23.1 \\
\hline Married & 50 & 76.9 \\
\hline \multicolumn{3}{|c|}{ Years of experience in cytotoxic drug administration: } \\
\hline$<5$ & 16 & 24.6 \\
\hline $5-<10$ & 18 & 27.7 \\
\hline$\geq 10$ & 31 & 47.7 \\
\hline \multicolumn{3}{|c|}{$8.83 \pm 5.93$} \\
\hline \multicolumn{3}{|c|}{$\begin{array}{l}\text { Attendance of training courses about safe handling } \\
\text { practices of cytotoxic drugs }\end{array}$} \\
\hline Yes & 12 & 18.5 \\
\hline No & 53 & 81.5 \\
\hline \multicolumn{3}{|c|}{ Adequacy of information received in training courses } \\
\hline Yes & 0 & 0 \\
\hline No & 65 & 100 \\
\hline \multicolumn{3}{|c|}{ Number of patients administered cytotoxic drug/day } \\
\hline Mean \pm SD & \pm 13. & \\
\hline
\end{tabular}

Regarding demographic characteristics of the studied nurses, table 1 shows that the mean age of the studied nurses was $33.51 \pm 8.59$, and $38.5 \%$ of them were at age between 30-40 years old. Moreover, (86.2\%) of them were females and $76.9 \%$ of the studied nurses were married. Regarding level of education of studied nurses, $72.3 \%$ of them were diploma and $47.7 \%$ of nurses under study had more than 10 years of experiences. However, $81.5 \%$ of them didn't attend training courses about safe handling practices of cytotoxic drugs, and all $(100 \%)$ of them hadn't sufficient information from these courses. As regard to the mean of number of patients received cytotoxic drugs by nurses per day, it was $16.14 \pm 13.62$ patients /day. 
Table (2): Percentage distribution of nurses' complaints regarding exposure to cytotoxic drugs (N=65)

\begin{tabular}{|l|c|c|}
\hline \multicolumn{1}{|c|}{ Items } & No & \% \\
\hline Having risk due to exposure to cytotoxic drugs & \multicolumn{1}{|l|}{} \\
\hline Yes & 44 & 67.7 \\
\hline No & 21 & 32.3 \\
\hline Regular check-up & 2 & 3.1 \\
\hline Yes & 63 & 96.9 \\
\hline No & \multicolumn{2}{|l|}{} \\
\hline Symptoms & 19 & 29.2 \\
\hline Dizziness & 12 & 18.5 \\
\hline Redness or flushed face & 50 & 76.9 \\
\hline Headache & 54 & 83.1 \\
\hline Hair loss & 10 & 15.4 \\
\hline High temperature & 7 & 10.8 \\
\hline Nausea & 9 & 13.8 \\
\hline Vomiting & 6 & 9.2 \\
\hline Diarrhea & 10 & 15.4 \\
\hline Loss of weight & 9 & 13.8 \\
\hline Abortion & 5 & 7.7 \\
\hline Early birth \& congenital fetus anomalies & 7 & 10.8 \\
\hline Irregular menstruation & 8 & 12.3 \\
\hline Skin rash \& Dermatitis & 41 & 63.1 \\
\hline Eye injury & 40 & 61.5 \\
\hline Sore throat & 19 & 29.2 \\
\hline Cough and bronchospasm. & 18 & 27.7 \\
\hline Difficulty breathing & 13 & 20.0 \\
\hline Bleeding or nasal discharge & 21.5 \\
\hline Frequent influenza & \multicolumn{2}{|l|}{} \\
\hline
\end{tabular}

As regard to health hazards among nurses due to exposure to cytotoxic drugs, Table 2 shows that $67.7 \%$ of the studied nurses were exposed to cytotoxic drug hazards and $96.9 \%$ of them don't make regular checkup. Regarding to the nurses' complaints as a result of exposure to cytotoxic drug, $83.1 \%$ complain from hair loss, $76.9 \%$ of them complain from headache, $63.1 \%$ complain from eye injury, and $61.5 \%$ complain from sore throat. While, only $13.8 \%$ of them complain from abortion and $7.7 \%$ complain from congenital fetus anomalies and early birth.

Table 3: Difference between mean Scores of nurses' knowledge regarding cytotoxic drugs safe handling pre and post guidelines intervention $(\mathrm{N}=65)$

\begin{tabular}{|l|c|c|c|c|c|c|}
\hline \multirow{2}{*}{ Knowledge items } & \multicolumn{2}{|c|}{ Pre-intervention } & \multicolumn{2}{c|}{ Post-intervention } & \multirow{2}{*}{ T-test } & \multirow{2}{*}{ P value } \\
\cline { 2 - 6 } & Mean & SD & Mean & SD & & \multirow{2}{*}{$0.000 *$} \\
\hline $\begin{array}{l}\text { - Cytotoxic drugs hazardous } \\
\text { effects }\end{array}$ & 5.85 & 1.89 & 8.91 & 1.89 & 19.771 & 0.000 \\
\hline - Methods of exposure & 8.54 & 2.69 & 10.62 & 1.56 & 12.405 & $0.000 *$ \\
\hline - Safe handling measures & 13.42 & 1.49 & 21.32 & 2.00 & 47.885 & $0.000 *$ \\
\hline Total knowledge & 27.80 & 4.88 & 40.85 & 3.48 & 46.542 & $0.000 *$ \\
\hline
\end{tabular}

${ }^{*} p \leq 0.001$ highly significant

In relation to the differences between mean scores of nurses' knowledge related to cytotoxic drugs safe handling pre and post implementation of safety guidelines, Table 3 reveals the highly statistically significant differences between mean scores of the pre and post guidelines intervention regarding cytotoxic drugs hazardous effects, ways of exposure and safe handling measures, as well between the mean scores of the total knowledge pre and post implementation of safety guidelines.

Table 4: Difference between mean scores of nurses' safe handling practices of cytotoxic drugs pre and post guidelines intervention $(\mathrm{N}=65)$

\begin{tabular}{|l|c|c|c|c|c|c|}
\hline \multirow{2}{*}{\multicolumn{1}{|c|}{ Items }} & \multicolumn{2}{|c|}{ Pre-intervention } & \multicolumn{2}{c|}{ Post-intervention } & \multirow{2}{*}{ T-test } & \multirow{2}{*}{ P value } \\
\cline { 2 - 5 } & Mean & SD & Mean & SD & & \\
\hline - Drug preparation & 8.37 & 0.74 & 14.42 & 0.75 & 176.86 & $0.000^{*}$ \\
\hline - Drug transportation & 1.12 & 0.33 & 1.80 & 0.40 & 11.58 & $0.000^{*}$ \\
\hline - Drug administration & 5.45 & 0.79 & 10.63 & 1.01 & 41.87 & $0.000^{*}$ \\
\hline - Drug discontinuation & 3.28 & 0.65 & 4.48 & 0.73 & 11.89 & $0.000^{*}$ \\
\hline $\begin{array}{l}\text { - Waste disposal and spillage } \\
\text { management }\end{array}$ & 5.00 & 0.64 & 5.95 & 0.76 & 18.67 & $0.000^{*}$ \\
\hline - Care of safety cabinet & 3.15 & 0.36 & 3.78 & 0.41 & 10.46 & $0.000^{*}$ \\
\hline - Documentation of exposure & 1.14 & 0.35 & 1.38 & 0.49 & 4.57 & $0.0002^{*}$ \\
\hline Total practices & 27.51 & 3.49 & 42.45 & 3.81 & 176.86 & $0.000^{*}$ \\
\hline
\end{tabular}

${ }^{*} p \leq 0.001$ highly significant 
As regards to the differences between mean scores of nurses' practices pre and post safety guidelines intervention, table 4 represents that, there were highly statistically significant differences between mean scores of the pre and post guidelines intervention as regards to drug preparation, drug transportation, drug administration, drug discontinuation, waste disposal and spillage management, care of safety cabinet and documentation of exposure, as well between the mean scores of the total practices.

Table (5): Difference between mean scores of nurses' attitude regarding cytotoxic drugs safe handling pre and post guidelines intervention $(\mathrm{N}=65)$

\begin{tabular}{|c|c|c|c|c|c|c|}
\hline \multirow{3}{*}{$\begin{array}{c}\text { Item } \\
\text { Attitude }\end{array}$} & \multicolumn{2}{|c|}{ Pre-intervention } & \multicolumn{2}{|c|}{ Post-intervention } & \multirow{2}{*}{ T-test } & \multirow{2}{*}{ P-value } \\
\hline & Mean & SD & Mean & SD & & \\
\hline & 38.66 & 1.81 & 42.66 & 1.64 & 20.78 & $0.000^{*}$ \\
\hline
\end{tabular}

Table 5 shows that, there is highly statistically significant difference between mean score of nurses' attitude related to cytotoxic drugs safe handling pre and post guidelines intervention.

Table (6): Percentage distribution of the factors associated with risk exposure of the studied nurses ( $\mathrm{N}=65)$

\begin{tabular}{|c|c|c|}
\hline Factors associated with risk exposure of the studied nurses & Yes & $\%$ \\
\hline \multicolumn{3}{|l|}{ Safe handling awareness of cytotoxic drugs: } \\
\hline Unaware of the safety measures when handling cytotoxic drugs. & 51 & 78.5 \\
\hline Inadequate in-service training and education. & 33 & 50.8 \\
\hline Nurses aren't encouraged to comply with wearing the protective equipment & 30 & 46.2 \\
\hline \multicolumn{3}{|l|}{ Adequacy of equipments } \\
\hline Unavailability of masks. & 37 & 56.9 \\
\hline Unavailability of gowns. & 37 & 56.9 \\
\hline Unavailability of eye protective. & 51 & 78.5 \\
\hline Unavailability of gloves. & 35 & 53.8 \\
\hline Unavailability of safe boxes for drug transportation & 54 & 83.1 \\
\hline \multicolumn{3}{|l|}{ Working environment } \\
\hline Availability of only one safety cabinet for drug preparation in the cancer center. & 27 & 41.5 \\
\hline No cooperation among the health team members. & 29 & 44.6 \\
\hline \multicolumn{3}{|l|}{ Workload } \\
\hline Limited time to wear PPE. & 6 & 9.2 \\
\hline Heavy work load. & 56 & 86.2 \\
\hline Wearing the protective equipment is uncomfortable and hinders my work. & 39 & 60.0 \\
\hline Increasing the patients' number. & 46 & 70.8 \\
\hline $\begin{array}{l}\text { The nurses are responsible for preparation and administration of cytotoxic drugs } \\
\text { for many patients daily. }\end{array}$ & 47 & 72.3 \\
\hline \multicolumn{3}{|l|}{ Administrative } \\
\hline Lack monitoring from supervisors. & 33 & 50.8 \\
\hline Unavailability of a procedure and policy book in the work area. & 65 & 100 \\
\hline $\begin{array}{l}\text { The protection of nurses from exposure to hazards effect of cytotoxic drugs isn't } \\
\text { a priority for the administration. }\end{array}$ & 37 & 56.9 \\
\hline
\end{tabular}

In relation to the factors associated with risk exposure, Table 6 shows that, $78.5 \%$ of the studied nurses stated that they were unaware of the safety measures for dealing with cytotoxic drugs inspite of $72.3 \%$ of them are responsible for preparation and administration of cytotoxic drugs for many patients daily. Also, $56.9 \%$ of them stated masks and gowns are unavailable all times, and $78.5 \%$ reported that eye goggle is unavailable. In addition, $60.0 \%$ of them consider wearing the protective equipment uncomfortable and hinders their work, $86.2 \%$ of nurses stated that heavy work load affect their following of safe handling practices and $70.8 \%$ mentioned that increasing the patients' number as a barrier. Finally, $50.8 \%$ reported inadequate in-service training and education and all of them $100 \%$ stated unavailability of a procedure book in the work setting.

\section{Discussion}

Cytotoxic drugs that are used to treat cancer cannot tell the difference between normal cells and cancer cells which can results in disruption of the growth and function of both healthy and diseased cells, resulting in toxic side effects for both treated patients and health care workers who are involved in activities such as transporting, preparing, administrating, cleaning of cytotoxic drugs spills, and handling of wastes. Nurses are among the main health care workers who are exposed to these drugs during these activities. Nurses require specialized knowledge, skills and attitude in order to ensure safety for both patients life and for their own safety $[15,16]$. This study was conducted to evaluate the effect of of cytotoxic drugs safety guidelines on awareness, handling practices and attitude of oncology nurses who involved in the preparation and administration of cytotoxic drugs. 
The present study revealed that the mean age of the nurses under study was $33.51 \pm 8.59$, and approximately two fifths of them were at age group between 30-40 years old. Majority of them was females and more than three quarters of the studied nurses were married. Regarding level of education of studied nurses, near three quarters of them had diploma degree and majority of nurses didn't attend training courses about cytotoxic drugs. These results are in agreement with Mohsen and Fareed, (2013) [17] who stated that the mean age of the study groups were $31.91 \pm 7.49$ and most of them were females. Regarding education they reported that two thirds of studied nurses had diploma degree and the majority of the studied group didn't trained previously about chemotherapy in their study that titled "chemotherapy safety protocol for oncology nurses: its effect on their protective measures practices".

Regarding nurses' knowledge about cytotoxic drugs safe handling, the results of this study showed that there was highly statistically significant difference between mean score of the total knowledge related to all items of cytotoxic drugs safe handling pre and post safety guidelines intervention. The improvement in nurses' knowledge post the safety guidelines intervention can be attributed to the effectiveness of the safety guidelines and teaching sessions as a useful tool to improve oncology nurses' knowledge about cytotoxic drugs. In addition, the desire of nurses to acquire knowledge in order to avoid the hazardous effects of the cytotoxic drugs they handled. Moreover, all nurses were willing to learn because majority of them reported that they didn't had training courses about cytotoxic drugs' safe handling despite had ten years or more of experiences in handling these drugs. The nurses also added that there was no procedure book or guidelines available at the cancer center to guide them during handling such drugs.

On the same line, Keat, Sooaid, Yun, and Sriraman, (2013) [3] reported that there was a significant improvement of knowledge levels among the nurses on cytotoxic drug handling, with comparison of a mean knowledge score in the first and the second assessment after implementation of a series of technical, educational and administrative support measures consisting of the initiation of closed-system cytotoxic drug reconstitution (CDR) services, courses, training workshops and guideline updates in their study that titled "improving safetyrelated knowledge, attitude and practices of nurses handling cytotoxic anticancer Drug: pharmacists' experience in a general hospital, Malaysia".

The results are also supported by Bolbol, Hassan, El-Naggar and Zaitoun, (2016) [18] who stated that the level of knowledge of the nurses about cytotoxic drugs was not satisfactory pre intervention which was due to lack of training courses related to cytotoxic drugs handling. But there was highly significant improvement in studied nurses' knowledge after intervention regarding definition of cytotoxic drugs, mood of exposure, risky behavior and handling contaminated materials in their study that titled "role of occupational health and safety program in improving knowledge and practice among nurses exposed to chemotherapy at zagazig university hospitals". In addition Karpagam, Mangalagowr and Aruna, (2017) [19] reported that there wsa a difference in the level of knowledge before and after administration of planned teaching programme regarding safe handling of chemotherapy drugs in their study that titled "effectiveness of planned teaching programme on safe handling of chemotherapy drugs among staff nurses".

Concerning nurses' safe handling practices, the findings of the present study showed the low mean score of nurses' practices pre safety guidelines intervention which may be due to lack of their knowledge about the hazards effect of cytotoxic drugs and preventive measures that can reduce the risk of these drugs during exposure. Unfortunately, the lack of nurses' knowledge leads to risky behaviors and inappropriate practices and handling during preparation of the drugs that were observed by the researchers such as not wearing goggle, receiving the drugs from the pharmacy in a plastic bag and not in a sealed containers, nurses prim the intravenous tubing after adding the cytotoxic drug to the intravenous solution which may increase the risk of skin burning or irritation, sometimes nurses prim the intravenous tubing on the floor and not into a gauze or basket, and write the name of patients and name of the drugs on the container but don't labeled it as a cytotoxic drugs to allow others to take care in handling these containers.

In addition, the researchers observed that nurses didn't wear gloves or other protective equipments such as gown, eye glasses and mask when they receive the prepared drugs from the cabinet, or during its administration, or even during inserting the intravenous access device, they didn't place plastic-backed absorbent pad to protect patient from droplet. Regarding to oral cytotoxic drugs, they put the dose on paper container and not into medicine cup because it is not available in the cancer center.

The previous results are in accordance with Elshamy, El-Hadidi, El-Roby and Fouda, (2010) [20] who reported that expelling air from syringes filled with CDs were common risky nursing activities in their study that titled "health hazards among oncology nurses exposed to CDs drugs". In addition, Shrestha, (2012) [21] mentioned that there was poor use of gloves, gowns and personal protective equipment by study nurses when handling patient waste, and when cleaning up spills. Moreover, Waheida, Abd-ELgaffar, and Atia, (2015) [22] stated that there was poor use of gloves, gowns and personal protective equipment among studied nurses when handling patient and cleaning up spills due to lack of knowledge. When handling CDs there was no use of gloves and surgical mask by study nurses but a very small number of them used all of the recommended 
protective equipment in their study that titled "evaluation of handling practices of oncology nurses during chemotherapy preparation and administration in menoufia oncology hospital".

Regarding nurses' total practices post safety guidelines intervention, the present study revealed that there were highly statistically significant differences between mean scores of nurses' total practices regarding drug preparation, drug transportation, drug administration, drug discontinuation, waste disposal and spillage management, care of safety cabinet and documentation of exposure pre and post implementation of safety guidelines. This may be due to the training that done during the practical sessions which showed actually the correct way of dealing with and safe handling technique of cytotoxic drugs. Additionally, the desire of oncology nurses to practice the steps during these sessions to be able to protect themselves of having side effects from these drugs and to save their patient's life. Moreover, the improvement in nurses' practice may be because of the distribution of guidelines to nurses which contained all information needed about cytotoxic drugs because these guidelines was designed and developed based on their learning needs.

The findings of the present study are in accordance with Khan, Khowaja and Ali (2012) [23] who reported that the majority of the nurses had poor performances in all three stages including pre administration, during administration and post administration of chemotherapy. However, during the skill observation process, the researcher observed that the study participants were not following the international standards for chemotherapy preparation and administration pre implementation of educational sessions. But post implementation of educational sessions, there was improving in the knowledge and skills of nurses in their study that titled "assessment of knowledge, skill and attitude of oncology nurses in chemotherapy administration in tertiary hospital Pakistan".

Also, Keat, et al., (2013) [3] reported that the mean score for overall ward practices was increased twofold, from 7.6-15.3 out of 20.0. All tested aspects including the drug preparation, transportation, storage, administration, spillage management and waste disposal and decontamination were significantly improved after the interventions in their study that titled "improving safety-related knowledge, attitude and practices of nurses handling cytotoxic anticancer Drug: pharmacists' experience in a general hospital, Malaysia”.

Regarding nurses' attitude pre implementation of safety guidelines, unfortunately, the nurses reported that wearing protective equipment is not necessary because even they wear it, they also at risk for hazards effects. They stated that wearing gloves prevent them from palpating the vein to insert intravenous access device and they aren't used to wear the eye goggle. They added that there is lack of training courses that held by the cancer center to aware them with the safety measures.

This result is in accordance with Boiano, Steege and Sweeney, (2014) [24] who stated that recommended practices are not always followed, despite the availability of safety guidelines developed by professional practice organizations in their study that titled "adherence to safe handling guidelines by health care workers who administer antineoplastic drugs". In addition, VerStrate, (2015) [25] reported that although the toxicity of chemotherapeutic agents is well documented, the nurses that participated in the survey reported a low overall use of safety precautions when administering chemotherapy in his study that titled "exploration of chemotherapy safe-handling practices and identification of knowledge deficits among oncology nurses in the ambulatory care setting".

Also, Ali, Arif and Pesnani, (2015) [26] demonstrated that more than two fifths of registered nurses think that PPE is not necessary while handling chemo drugs, most of the registered nurses agreed that training is important for handling of cytotoxic drug, however, more than half of them answered that sufficient education and training and hospital policy are not effective to improve cytotoxic drug handling, and more than one third of the registered nurse agreed that they don't handle chemo appropriately.

Concerning nurses' attitude toward handling of cytotoxic drugs, the present study showed that there is highly statistically significant difference between mean scores of nurses' attitude related to cytotoxic drugs safe handling pre and post the safety guidelines intervention. The change in nurses' attitude toward handling cytotoxic drugs may be because the nurses want to avoid or minimize the side effects or the symptoms and complains they already had due to exposure to these drugs.

This result is contradicted with Chaudhary and Karn, (2012) [14] who reported that no significant differences were found in the frequency of risky behaviors in working environment regarding CDs and none of the nurses were using the four protective equipments necessary during the handling of CDs in their study that titled "chemotherapy-knowledge and handling practice of nurses working in a medical university of Nepal". But in accordance with Bolbol, Hassan, El-Naggar and Zaitoun, (2016) [18] who reported that there is significant improvement in studied nurses' attitude and practice after intervention regarding the use of personal protective equipment during handling patients' waste and cleaning up spills. The nurses use them poorly before intervention because they don't know that contact with patient waste and cleaning up spills can expose them to hazards of CDs. Additionally, Keat, et al., (2013) [3] demonstrated that the interventions had led to the change of nurses' attitude towards certain safety-related issues and the percentage of nurses who believed that using PPE was not necessary during cytotoxic drug handling was also tremendously decreased in their study that titled 
"improving safety-related knowledge, attitude and practices of nurses handling cytotoxic anticancer drug: pharmacists' experience in a general hospital, Malaysia".

In relation to hazards effect of cytotoxic drugs, the findings of the present study revealed that more than two thirds of nurses under study were exposed to cytotoxic drug hazards and most of them don't have regular check-up of their health. In this study majority of nurses reported that they had hair loss and more than three quarters of them complain from headache. Approximately two thirds of them reported eye irritation and sore throat. About two fifths of nurses reported cough, bronchospasm and difficult breathing. One fifth of nurses reported that they had frequent influenza and few of them had previous abortion, congenital fetus anomalies and early birth. The previous results may be because oncology nurses are not committed with the safe handling practices such as wearing goggle and mask. Sometimes they take their drinks in the same area of drug administration and may be due to the long period they spend in dealing with and exposure to cytotoxic drugs, where less than half of them had more than ten years of experience in handling cytotoxic drugs. It is well known that the increased risk of cytotoxic drugs exposure is correlated with the number of drugs handled and long term esposure to these drugs [27].

The findings of this study are consistent with Bolbol, Hassan, El-Naggar and Zaitoun, (2016) [18] who mentioned that near two thirds of nurses under study reported that they had bronchospasm as a health hazards effect of cytotoxic drugs, more than half of them had reproductive hazards (such as menstrual changes), two fifths reported abortions, less than one fifth had infertility, more than two thirds had headache and eye affection, near one quarter of nurses reported skin and mucous membrane affection and few of them had premature labour,. Also Hanafi et al, (2015) [1] added that the most prevalent adverse reactions of cytotoxic drugs handling in nursing staff was burning sensation in the eyes, while most of the nurses don't wear protective goggles during preparing the drugs. Also the majority of the nurses mentioned inflammation in their mouth which shows that simple 3-layered masks are not as protective as surgical masks.

In relation to the barriers or factors affecting using of safety measures during handling cytotoxic drugs, the present study showed that, slightly more than half of studied nurses stated that there is inadequate in-service training and education conducted by the administrative staff in the cancer center about safe handling of cytotoxic drugs despite that nurses are the persons who are responsible for preparing and administering of these drugs, and all of them stated that there is no standard guidelines for cytotoxic safe handling procedure available in the work place and more than three quarters of nurses reported that they are unaware of safe handling practices of cytotoxic drugs.

These finding are contradicted with Elshamy et al., (2010) [20] and Chaudhary and Karn, (2012) [14] who reported that fewer nurses mentioned that there are nursing care guidelines for procedures for dealing with patients receiving CDs as well as presence of in-service training programs. Also, Kyprianou, et al, (2010) [6] stated that most of the nurses were aware of the potential hazards of handling antineoplastic agents despite not having received specialized training on safe handling practices and they did not receive annual medical surveillance as a result of handling antineoplastic agents in their study that titled "Knowledge, attitudes and beliefs of Cypriot nurses on the handling of antineoplastic agents".

In the present study, more than half of the studied nurses stated that not all personal protective equipments (PPE) are available all time such as gown, goggle and mask and there is one safety cabinet in the whole center to prepare cytotoxic drugs for the outpatients because the flow of patients is high in the outpatient clinic ranged from 30-40 patients daily, and nurses in the wards are allowed to prepare the CDs in the safety cabinet only if the nurses in the outpatient clinics finished their drug's preparation. So, sometimes they prepare the cytotoxic drugs outside the safety cabinet.

These results are in accordance with VerStrate, (2015) [23] who stated that participants reported barriers to using safety precautions included unavailability of PPE; difficulty in obtaining chemotherapydesignated PPE; the lack of a policy that required its use; nurses feeling physically uncomfortable (too hot) when wearing PPE; and coworkers around them not using protective equipment in his study that titled "exploration of chemotherapy safe-handling practices and identification of knowledge deficits among oncology nurses in the ambulatory care setting". Also, results are in agreement with Kyprianou, et al, (2010) [6] who reported that most of the nurses in the study reported that they were preparing antineoplastic drugs in a Biological Safety Cabinet (BSC).

Oncology nurse in this study also added other barriers that hinder their safe handling of cytotoxic drugs such as, work pressure due to under-staffing and high patient number. Sometimes two nurses only available to administer cytotoxic drugs for 40 patients and this prevent nurses from wearing PPE due to lack of time. In addition lack of awareness with the importance and hazards of cytotoxic drugs. So the oncology nurses should have advanced knowledge about safe handling practices of cytotoxic drugs and be competent in their skills to be able to administer the drugs safely to cancer patients and reduce the chances of errors or unsafe practices and to elevate their sense of well-being. 


\section{Conclusion}

The results of this study concluded that implementation of the cytotoxic drugs safe-handling guidelines had positive effect on improving nurses' knowledge related to (cytotoxic drugs hazardous effects, mthods of exposure, safe handling measures), nurses' practice related to (drug preparation, transportation, administration, discontinuation, waste disposal and spillage management and care of safety cabinet) and nurses' attitude of the oncology nurses working in the cancer center affiliated to Ain Shams University Hospital.

\section{Recommendations}

- Conducting periodic in-services training program for oncology nurses who are handling cytotoxic drugs in the cancer center to improve knowledge and safe handling measures and reduce the harmful effects of these drugs among nurses is considered of great importance.

- It is recommended to continuously monitoring nurses who are working with CDs by administrative staff to ensure safe handling of cytotoxic drugs by oncology nurses.

- A guidance book about nursing policy, procedures and safe handling of cytotoxic drugs should be available in the cancer center to guide nurses in dealing with cytotoxic drugs.

\section{References}

[1]. S. Hanafi, H. Torkamandi, S. Bagheri, M. Tavakoli, N. Hadavand and M. Javadi, Safe handling of cytotoxic drugs and risks of occupational exposure to nursing staffs, J Pharm Care; 3(1-2), 2015, 11-15.

[2]. C.H. Yarbro, D. Wujcik, B.H. Gobel, Cancer nursing: principles and practice, (Jones and Bartlett Publishers London 2011), $7^{\text {th }}$ ed, p. 392.

[3]. C.H. Keat, N.S. Sooaid, C.Y. Yun and M. Sriraman, Improving safety-related knowledge, attitude and practices of nurses handling cytotoxic anticancer drug: pharmacists' experience in a general hospital, Malaysia, Asian Pacific J Cancer Prev; 14 (1), 2013 , 6973.

[4]. NIOSH (National Institute for Occupational Safety and Health). 2008. Workplace Solutions: Personal Protective Equipment for Health Care Workers who Work with Hazardous Drugs. DHHS (NIOSH) Publication No. 2009-106. Available at http://www.cdc.gov/niosh/docs/wp-solutions/2009-106/pdfs/2009- 106.pdf. Accessed 23 Nov. 2016.

[5]. T.H. Connor, S.F. Eckel, M.A.McDiarmid, M. Polovich and LA. Power, Safe handling of hazardous chemotherapy drugs in limited-resource settings, (Pan American Health Organization (PAHO) and World health organization (WHO) Publishers Washington 2013), pp. 1-62.

[6]. M. Kyprianou, M. Kapsou, V. Raftopoulos, E.S. Soteriades, Knowledge, attitudes and beliefs of cypriot nurses on the handling of antineoplastic agents, European Journal of Oncology Nursing; 14 (2010): 278-282.

[7]. M. Villarini, R. Dominici, R. Piccinini, Assessment of primary, oxidative and excision repaired DNA damage in hospital personnel handling antineoplastic drugs, Mutagenesis; 26(3), 2011, 359-369.

[8]. C.C. Lawson, C.M. Rocheleau and E.A. Whelan, Occupational exposures among nurses and risk of spontaneous abortions, Am. J.Obstet. Gynecol; 206:327, 2012, .1-8.

[9]. S.I. Al-Azzam, B.T. Awawdeh, K.H. Alzoubi, Y.S. Khader and A.M. Alkafajei, Compliance with safe handling guidelines of antineoplastic drugs in jordanian hospitals, J Oncol Pharm Pract; 21(1), 2015, 3-9.

[10]. Occupational Safety and Health Administration, Controlling occupational exposure to hazardous drugs. OSHA Safety and Health Topics: Hazardous Drugs 2016 www.osha.gov/?SLTC/?hazardousdrugs/?controlling occex hazardousdrugs.html Accessed March $10,2017$.

[11]. M. Polovich, and P.C. Clark, Nurses' use of hazardous drug safe handling precautions, dissertation, Georgia State University, 2010; pp. 1-151. Available at http://scholarworks.gsu.edu/nursing diss/21. Accessed 3 September 2016.

[12]. [M. Polovich, M. Olsen and K.B. LeFebvre, Chemotherapy and biotherapy guidelines and recommendations in practice, (Oncology Nursing Society Pittsburgh 2014), $4^{\text {th }}$ ed, pp. 65-73.

[13]. M. Polovich, and P.C. Clark, Factors influencing oncology nurses' use of hazardous drug safe-handling precautions, Oncology Nursing Forum, 2012, pp. 1-151. Available at http://scholarworks.gsu.edu/nursing diss/21. Accessed 5 Nov. 2016.

[14]. R. Chaudhary, and B.K. Karn, Chemotherapy-knowledge and handling practice of nurses working in a medical university of Nepal, Journal of Cancer Therapy; 3, 2012, 110-114.

[15]. Public services health and safety association (2013). Safe Handling of Hazardous Drugs in Healthcare. Retrieved from https://www.pshsa.ca/wp-content/uploads/2013/11/PSHSA-Whitepaper-Safe-Handling-of-Hazardous-Drugs-in-Healthcare.pdf. accessed on 20 Feb.2017.

[16]. S. Gazal, M. Georgeos, A. Issa, Assessment knowledge and quality of nursing practices at chemotherapy management at tishreen university hospital, tishreen universi ty, Journal for Research and Scienti fic Studies - Health Sciences Series; 37 (1), 2015 , 197207.

[17]. M.M. Mohsen and M.E. Fareed, Safety protocol for oncology nurses: It's effect on their protective measures practices, International Journal of Medical, Health, Biomedical, Bioengineering and Pharmaceutical Engineering; 7(9), 2013, 529-537.

[18]. S.A. Bolbol, A.A. Hassan, S.A. El-Naggar and M.F. Zaitoun, Role of occupational health and safety program in improving knowledge and practice among nurses exposed to chemotherapy at zagazig university hospitals, Egyptian Journal of Occupational Medicine; 40 (2), 2016, 219-235.

[19]. K. Karpagam, P. Mangalagowr and S. Aruna, Effectiveness of planned teaching programme on safe handling of chemotherapy drugs among staff nurses, Int J Pharm Bio Sci; 8(1), 2017, (B) 180-184.

[20]. K. Elshamy, M. El-Hadidi, M. El-Roby and M. Fouda, Health hazards among oncology nurses exposed to CDs drugs, Afr J Haematol Oncol; 1(3), 2010, 70-78.

[21]. J. Shrestha, A Study to assess the effectiveness of structured teaching program on knowledge regarding safe handling and administration of cytotoxic drugs among nurses in selected hospital, BANGALORE 2012. Available at http://www.rguhs.ac.in/cdc/onlinecdc/uploads/05_N134_40726.doc. Accessed on 12 April 2017.

[22]. S.M. Waheida, S.I. Abd-ELgaffar and G.A. Atia, Evaluation of handling practices of oncology nurses during chemotherapy preparation and administration in menoufia oncology hospital, International Journal of Novel Research in Healthcare and Nursing; 2(3), 2015, 107-119. 
[23]. N. Khan, K.Z. Khowaja and T.S. Ali, Assessment of knowledge, skill and attitude of oncology nurses in chemotherapy administration in tertiary hospital Pakistan, Open Journal of Nursing; 2, 2012, 97-103.

[24]. J.M. Boiano, A.L. Steege and M.H. Sweeney, Adherence to safe handling guidelines by health care workers who administer antineoplastic drugs, Journal of Occupational and Environmental Hygiene; 11(11), 2014, 728-740.

[25]. C.A. VerStrate, Exploration of chemotherapy safe-handling practices and identification of knowledge deficits among oncology nurses in the ambulatory care setting, doctoral dissertations, Grand Valley State University 2015. Available at http://scholarworks.gvsu.edu/dissertations. Accessed on 22 March 2017.

[26]. F.B. Ali, S. Arif and F. Pesnani, Association of knowledge on the attitude and practice of registered nurses regarding handling of cytotoxic drugs in a tertiary care hospital in karachi Pakistan, International Journal of Novel Research in Healthcare and Nursing; 2(3), 2015, 73-76.

[27]. S. Orujlu, H., Habibzadeh, M.J.Z. Sakhvidi and M. Hajaghazadeh, Knowledge, attitude, and performance of oncology nurses handling antineoplastic drugs in hospitals of urmia university, Iran, International Journal of Occupational Hygiene; 8(1), 2016, 1421. 